\title{
CONTROL OF HOSPITAL ACQUIRED INFECTION IN BANGLADESH - AN ENDEAVOR TO BE STRENGTHENED
}

Nosocomial or hospital acquired infection is a major cause of morbidity and mortality of patients attending the healthcare facilities all over the world. The issue of infection associated with medical practice probably dates back to over two thousand years when the medical healer started to practice surgical procedures. ${ }^{1}$ In the last two hundred years it has emerged as a matter of great concern with the rapid advancement of medical science. In the 1800 s as many as $80 \%$ of all operations ended in infection. ${ }^{2}$ For a long time medics refused to acknowledge the fact that infection could be afflicted by the healer during treatment until in mid $19^{\text {th }}$ century, when Ignaz Philip Semmelweis in Vienna demonstrated the relationship between hand washing with chlorinated water and reduction of puerperal sepsis. He successfully demonstrated a dramatic reduction in the incidence of puerperal sepsis from over $8 \%$ to $2.3 \%$ only by insisting on stringent hand washing with a solution of chlorinated water. ${ }^{2}$ The importance of controlling hospital infection was finally recognized by the work of Joseph Lister in mid sixties of $19^{\text {th }}$ century by publication of his landmark paper 'On the Antiseptic Principle in the Practice of Surgery' in the British Medical Journal. He recognized the role of microbes and the use of carbolic acid, an antiseptic solution, in controlling surgical wound infections. These observations provided the basis for control of hospital acquired infections and thereby the importance of infection control was conceptualized. However, the introduction of penicillin in 1941 brought a negative blow to infection control practices in hospitals on a false perception that 'penicillin the magic bullet' would readily alleviate this problem. As a result, there was rapid decline in interest in hospital infection control activities. But this euphoria did not last long because of the outbreak of large staphylococcal pandemics in the 1950s which resulted in renewed interest on infection control programs in hospitals. ${ }^{3}$

Today in USA, over 2 million people acquire nosocomial infection each year causing about 90, 000 deaths and costing US\$ 4 to 11 billion. ${ }^{4}$ Today surveillance programs estimate the rate of this infection as $5-10 \%$ of hospital admissions all over the world. ${ }^{4}$ Bangladesh is no exception. Systematic studies on the magnitude and extent of the problem are lacking, but a study conducted in 2004 in BIRDEM hospital, excluding burn, neonatal and adult intensive care units, has documented the rate of hospital acquired infection as $2.4 \% .{ }^{5}$ Hospital acquired infection is not only responsible for increased morbidity or mortality but it exerts significant economic pressure on the national healthcare sector of all countries of the world and more so where the resources are meager. Nosocomial infection increases the cost of treatment due to prolongation of hospital stay, use of expensive antibiotics for emerging multiple antibiotic resistant bacteria like methicillin resistant Staphylococcus aureus (MRSA), extended spectrum beta lactamase (ESBLs) and metalo-beta lactamse (MBLs) producing organisms. In Bangladesh, a limited single study has recorded the mean duration of hospital stay is significantly long (20 to 26 days) for cases who acquired hospital infection compared to non-infected cases ( 9.5 days). ${ }^{6}$ In a multi-center study involving four geographic divisions of Bangladesh, the rate of isolation of MRSA from hospital patients ranged between $32-63 \% .^{7}$ Another study conducted in a referral hospital of Dhaka city reported $43.2 \%$ and $39.5 \%$ of $E$. coli and K.pneumoniae as ESBL phenotypes respectively. ${ }^{8}$ The situation is even dismal in high risk areas of the hospital like intensive care units (ICU). All the isolates from an ICU of BIRDEM hospital were highly resistant $(>80 \%)$ to cephalosporins and fluoroquinolones. ${ }^{9}$ This entire scenario invites the urgent need for initiation of a systematic infection control program in all hospitals of the country.

In Bangladesh, infection control program in hospitals has been recognized only in early 2000 . Only few hospitals of the country have designated infection control programs and probably none has an antibiotic policy. There is also no established infection control policy and surveillance system in district and tertiary care hospitals. Recently, provision for infection control nurse has been made in few teaching public hospitals of the country. There is little in the undergraduate curriculum about infection control and its importance. Our medical and nursing students are taught very little 
about nosocomial infection and ways of reducing its spread. They graduate without an adequate knowledge on how to reduce infections. It is time to include infection control in our undergraduate and postgraduate curricula. Hospitals should have strict guidelines and review measures. In addition, efforts should be made to establish and strengthen microbiology laboratories to support management and control of health-careassociated infections. This will not only reduce patient morbidity, but also reduce the use of antibiotics and health care costs of the country. If we do not act today, we are destined to pay the price tomorrow in the form of increased sufferings of the patients, unwanted drainage of meager resources and turning successful treatment into failures! Therefore, "an effective infection control program will relief patients from unwarranted sufferings and grant medics to enjoy pride in their endeavor."

\section{J. Ashraful Haq \\ Professor \\ Department of Microbiology \\ Ibrahim Medical College}

\section{References}

1. Miller JT, Rahimi SY, Lee M. History of infection control and its contributions to the development and success of brain tumor operations. Neurosurgery Focus 2005; 18(4): 1-5.

2. Jessney B. Joseph Lister (1827-1912): a pioneer of antiseptic surgery remembered a century after his death. J Med Biography 2012; 20(3): 107-10.
3. Mehtar S. Importance of infection control in Wenzel R, Edmond M, Pittet D, Devaster JM, Brewer T, Geddes A, Butzer JP. (ed). A guide to infection control in the Hospital. B.C. Decker Inc. Hamilton London, 1998; 1-4.

4. Samuel SO, Kayode OO, Musa OI, Nwigwe GC, Aboderin AO, Salami TAT, Taiwo SS. Nosocomial infections and the challenges of control in developing countries. African Journal of Clinical And Experimental Microbiology 2010; 11(2): 102-110.

5. A survey on hospital acquired infection in BIRDEM hospital. Infection Control Unit, BIRDEM 2004.

6. Mohiuddin M, Haq JA, Hoq MM, Huq F. Microbiology of nosocomial infection in tertiary hospitals of Dhaka city and its impact. Bangladesh J Medical Microbiology 2010; 4: 32-38.

7. Haq JA, Rahman MM, Haque Asna SMZ, Hossain MA, Ahmed I, Haq T and Morshed MAHG. Methicillin-resistant Staphylococcus aureus in Bangladesh-a multi-centre study. International Journal of Antimicrobial Agents 2005; 25: 276-277.

8. Rahman MM, Haq JA, Hossain MA, Sultana R, Islam F, Islam AHMS. Prevalence of extended-spectrum$\beta$ lactamase-producing Escherichia coli and Klebsiella pneumoniae in an urban hospital in Dhaka, Bangladesh, International Journal of Antimicrobial Agents 2004; 24: 508-510.

9. Barai L, Kaniz F, Haq J Ashraful, Faruq MO, Ahsan ASMA, Morshed MAHG, Hossain MB. Bacterial profile and their antimicrobial resistance pattern in an intensive care unit of a tertiary care hospital in Dhaka. Ibrahim Med. Coll. J. 2010; 4(2): 66-69. 